This item was submitted to Loughborough's Research Repository by the author.

Items in Figshare are protected by copyright, with all rights reserved, unless otherwise indicated.

\title{
CLEAR design: developing an electronic copyright management system for Project ACORN
}

PLEASE CITE THE PUBLISHED VERSION

http://dx.doi.org/10.1108/eb045648

PUBLISHER

Emerald Group Publishing Limited @ Elizabeth Gadd

VERSION

AM (Accepted Manuscript)

LICENCE

CC BY-NC-ND 4.0

REPOSITORY RECORD

Gadd, Elizabeth A., Richard Goodman, and Adrienne Muir. 2019. "CLEAR Design: Developing an Electronic Copyright Management System for Project ACORN”. figshare. https://hdl.handle.net/2134/9686. 
This item was submitted to Loughborough's Institutional Repository (https://dspace.lboro.ac.uk/) by the author and is made available under the following Creative Commons Licence conditions.

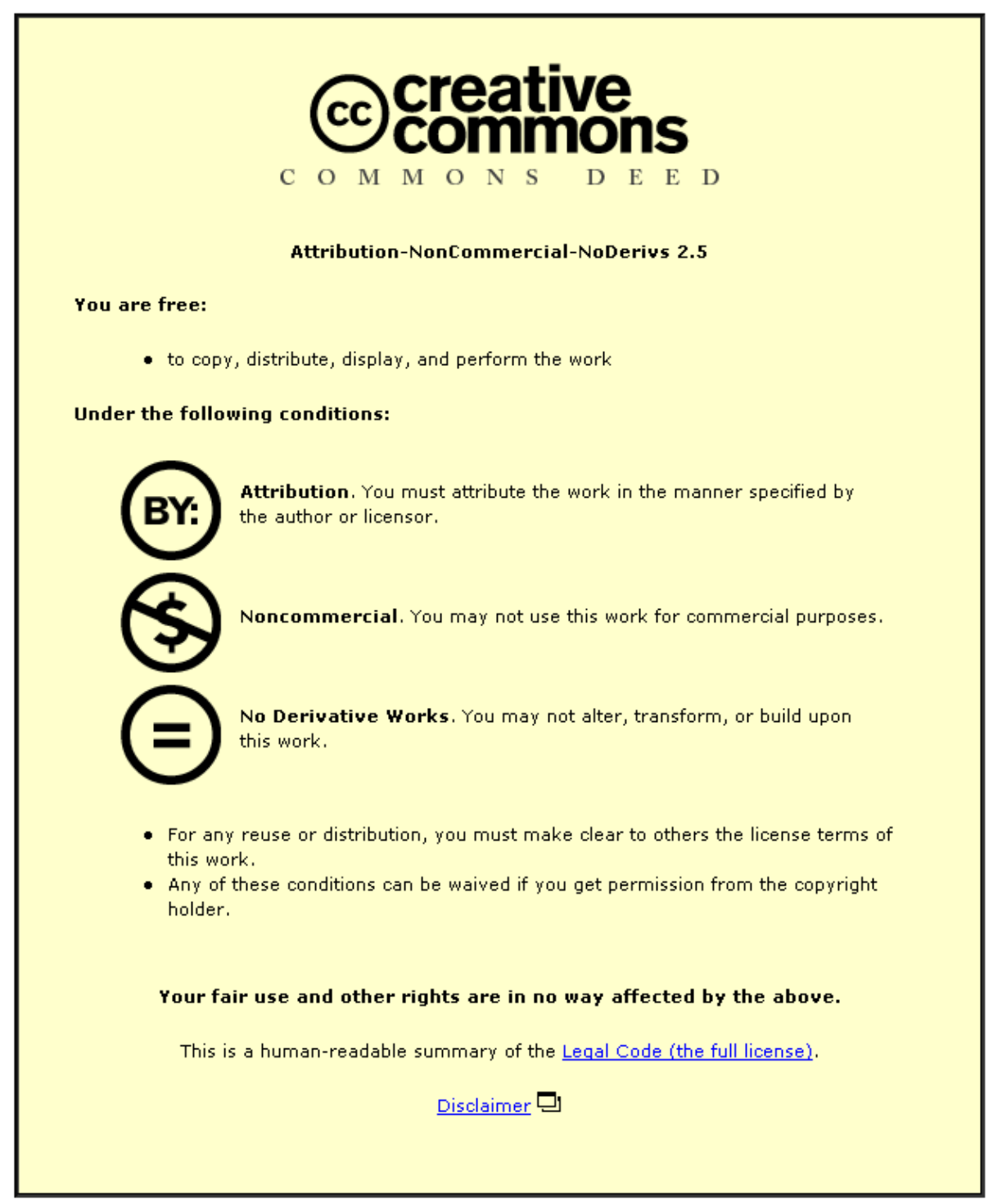

For the full text of this licence, please go to: http://creativecommons.org/licenses/by-nc-nd/2.5/ 


\title{
CLEAR design: developing an Electronic Copyright Management System for Project ACORN
}

\author{
Elizabeth Gadd, Richard Goodman and Adrienne Muir \\ Project ACORN, Loughborough University, Loughborough, Leicestershire, \\ LE11 3TU. E.A.Gadd@ Iboro.ac.uk, R.Goodman@ Iboro.ac.uk, Adrienne.Muir@ \\ bl.uk
}

\begin{abstract}
:
Outlines the copyright clearance difficulties faced by librarians in the development of the Electronic Library and states the need for an electronic copyright management system (ECMS) to jog the clearance process and to protect electronic documents. Reports the absence of a suitably priced commercially avail- able ECMS tor the academic sector and describes the design process for the eLib project ACORN's Rights Management system entitled CLEAR (Copyright Licensed Electronic Access to Readings) based on Microsoft Access. Describes the functionality of the CLEAR database and concludes that it might provide a template for other institutions in the design of subsequent ECMSs.
\end{abstract}

\section{Introduction}

An increasing amount of research and development work in digital libraries is being carried out worldwide. In the UK, work in this area has been carried out as part of the higher education sector Electronic Libraries Programme (elib).

(ukoln.bath.ac.uk/services/elib) Elib is funded by the Joint Information Systems Committee (JISC) of the UK Higher Education Funding Councils. The UK Office for Library Networking (UKOLN) (ukoln.bath.ac.uk) is another initiative jointly supported by the JISC and the British Library Research and Innovation Centre (BLRIC). Project EARL is a consortium of UK public libraries and associated organisations, established to develop the role of public libraries in providing library and information services over networks. (www.earl.org.uklinformation/about.html). In the United States, the National Science Foundation's Digital Libraries Initiative (www.cise.nst.gov/iis/dli_home.html) has just awarded funding to six research projects developing new technologies for digital libraries and the European Commission has funded much research through its Telematics for Libraries programme.

While new technology presents a great opportunity to provide new and better library services and to extend access to information, many projects involved in setting up such services have been hindered by copyright problems. British copyright law extends to electronic copying of material. However, there are problems with defining exactly what is meant by copying in a digital environment. Therefore, it is unclear whether the fair dealing and library privileges exceptions apply to electronic use of 
copyright material. Technically, accessing information electronically involves making more than one copy of the item and the Copyright, Designs and Patents Act

1988 (CDPA88) states that 'copying in relation to any description of work includes the making of copies which are transient or are incidental to some other use of the work' as an infringing act. (1993, ch. 48, section 17). Publishers have been wary of recognising fair dealing or library privileges in the digital environment and are worried that electronic access will facilitate infringing use of their material.

Currently, if Libraries are unable to make the copies they require under the CDPA88, they turn to licences, such as the Copyright Licensing Agency's (CLA) Higher Education licence. (www.cla.co/www/sectors.htm\#HE). However, since the UK's reproduction rights organisation is not currently authorised to clear electronic rights on behalf of publishers, libraries are obliged to seek permission to make material available electronically from individual publishers. It may be that this will change if the CLA achieves the proposed mandate from their rights holders to licence digitisation. However, the fact that not all rights holders are prepared to allow such an intermediary to handle their print copyright licensing, does not bode well for a comprehensive digitisation licensing scheme. For the foreseeable future Higher Education Institutions (HEis) will need to handle their own electronic copyright negotiations with at least some, if not most rights holders.

\section{"Publishers have been wary of recognising fair dealing or library privileges in the digital environment and are worried that electronic access will facilitate infringing use of their material."}

Copyright permission seeking is a complicated and time consuming process. References need to be obtained in good time, and identifying, approaching, and negotiating with rights holders involves many exchanges of information. Libraries who secure per- mission from rights holders will be subject to certain conditions, including controlling and monitoring access to material and possibly making payments. The whole process of obtaining electronic copyright clearance and monitoring the use of electronic col- lections needs to be managed.

Several initiatives in the field of electronic copyright management have been introduced in this area over the last few years. Some have been publicly funded research projects, such as IMPRIMATUR (www.imprimatur.alcs.co.uk/) funded by the European Commission Esprit Programme, others have been developed by commercial organisations. (www.iielr.dmu.ac.uk!Projects/ERCOMS/ercomsm.html). However, a study carried out for the elib project ERCOMS (Electronic Reserves Copyright Management System), (Ibid.) showed that at that time there was little software available suitable for the purposes of academic libraries. This was also the finding of another elib project, Project ACORN (Access to Course Readings across Networks). (acorn.lboro.ac.uk) 


\section{Permissions}

seeking for Project

ACORN

Project ACORN was

based at

Loughborough

University and was set

up to develop a

transferable model for

the process of providing

electronic access to

short-loan or reserve

journal articles in

Higher Education

Institutions (HEis). A unique feature of the project was the

partnership of Swets \& Zeitlinger, B.V.

(www.swets.nl/), the subscription agent, who were exploring the role for an intermediary in terms of copyright clearance and digitisation. In order to build up a critical mass of material for the collection, ACORN staff sought permission to digitise articles that had been designated by academics as being high-demand readings for undergraduates. In order to manage the large volume of information relating to the permission-seeking process, to protect and log use of the copyright materials once available, and to make payments back to rights holders, the ACORN team recognised the need for an ECMS. Having found that there were no suitably priced systems available commercially, the project decided to develop its own ECMS. The result was the two-part ACORN system. This consisted of a delivery mechanism which protected electronic documents with six levels of security (IP address authentication, user- name and password authentication, copyright scripts on each page on-screen and printed out, disabled cut/copy/paste functions, watermarked user ID/date/time on print-outs, and comprehensive usage tracking) in combination with the CLEAR (Copyright Licensed Electronic Access to Readings) rights management database which used Microsoft Access. This article describes the design and functionality of the CLEAR element of the ECMS. 


\section{Designing CLEAR}

The first stage in the design process was to map the information flows that made up the copyright permission seeking operation (Figure 1). The map illustrates the centrality of the ECMS in the three main permission seeking activities: 1) receipting reading lists from academics, 2) negotiating permissions and payment with rights holders and 3) obtaining the electronic copies. The next stage was to create a comprehensive list of the data the ECMS would need to store, and to normalise it into appropriate tables of related information. Relationships between the tables were then created in Microsoft Access so that when data was entered in one part of the database, it would automatically be updated in the rest of the tables. The ensuing relationship entity model is illustrated in Figure $2.1 \mathrm{n}$ order for the database to work successfully; a unique identifier was required for each publisher, journal and journal article. As there was no standard item identifier at the launch of the project, it was decided to adopt Swets \& Zeitlinger's proprietary publisher and journal identification system, and to extend it to relate to individual articles as well. These identifiers took the form of a three digit country code (for example 808 for the UK), and a five character publisher code (for example 'ROUT' for Routledge). Thus 808ROULT would form the publisher identifier (PID). A three-digit number added to the PID would represent a particular journal relating to the publisher (for example 808ROULT001). This became the Title identifier (TID). ACORN took this one step further by adding a decimal point and three further digits to represent an article in that journal (for example 808ROULT001.023) - an article identifier (AID). These identifiers form the basis of the CLEAR database. There are now other initiatives acclaimed of which future ECMSs could work, the most acclaimed of which is the Digital Object Identifier (DOI) system (www.doi.org/indew.html) originally designed by the Association of American Publishers in collaboration with the Corporation for National Research Initiatives.

\section{Database development}

In the first phase of the project, CLEAR needed only to deal with one semester's worth of information. The Phase One reading list data was uploaded from an Excel

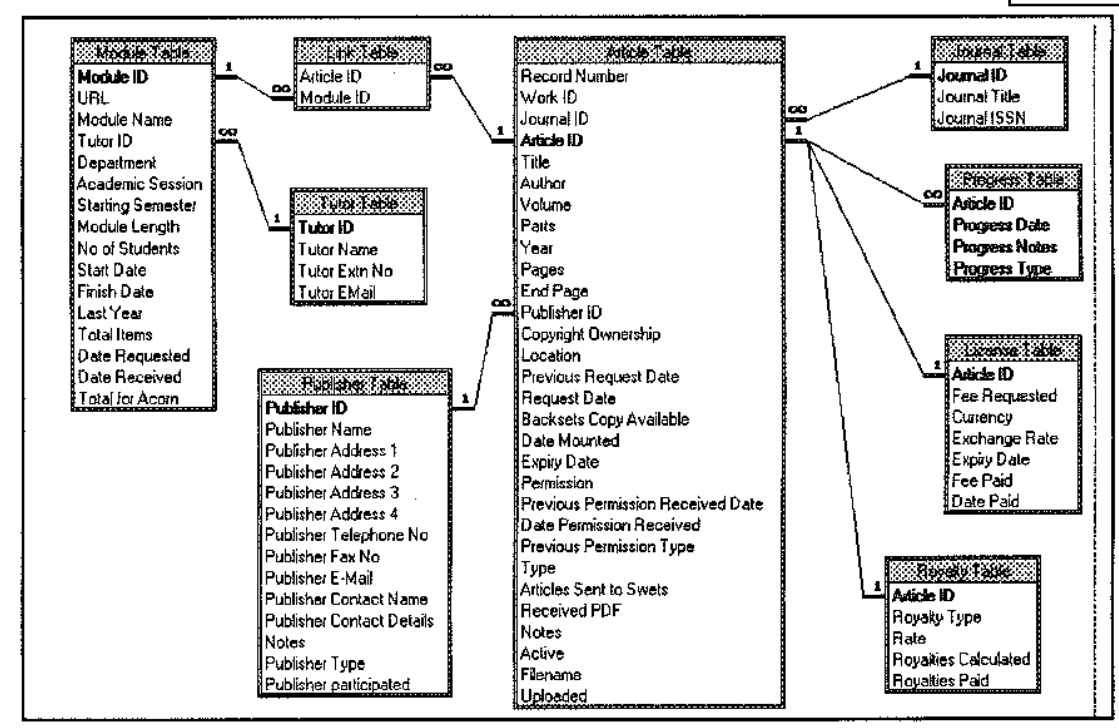

Spread sheet that a Library

Assistant had prepared in advance of the project. In the second phase of the project, CLEAR needed to distinguish between Semester Two and Semester One details 
ensuring that only the current semester's data appeared in reports and forms. In addition, it needed to deal with articles and modules that were duplicated across both semesters, and to distinguish between those publishers who had been approached before, and those who had not. Also, because reading list data was uploaded from Excel in Phase One, and now needed to be entered manually, a reading list entry form was required. Work is currently being undertaken to develop CLEAR one step further into an even -more generic product.

Improvements include the ability to deal with multiple years of information with current data appearing automatically, and the development of a networked version of the database which allows for, and logs data entry by, concurrent users.

\section{Figure 3.}

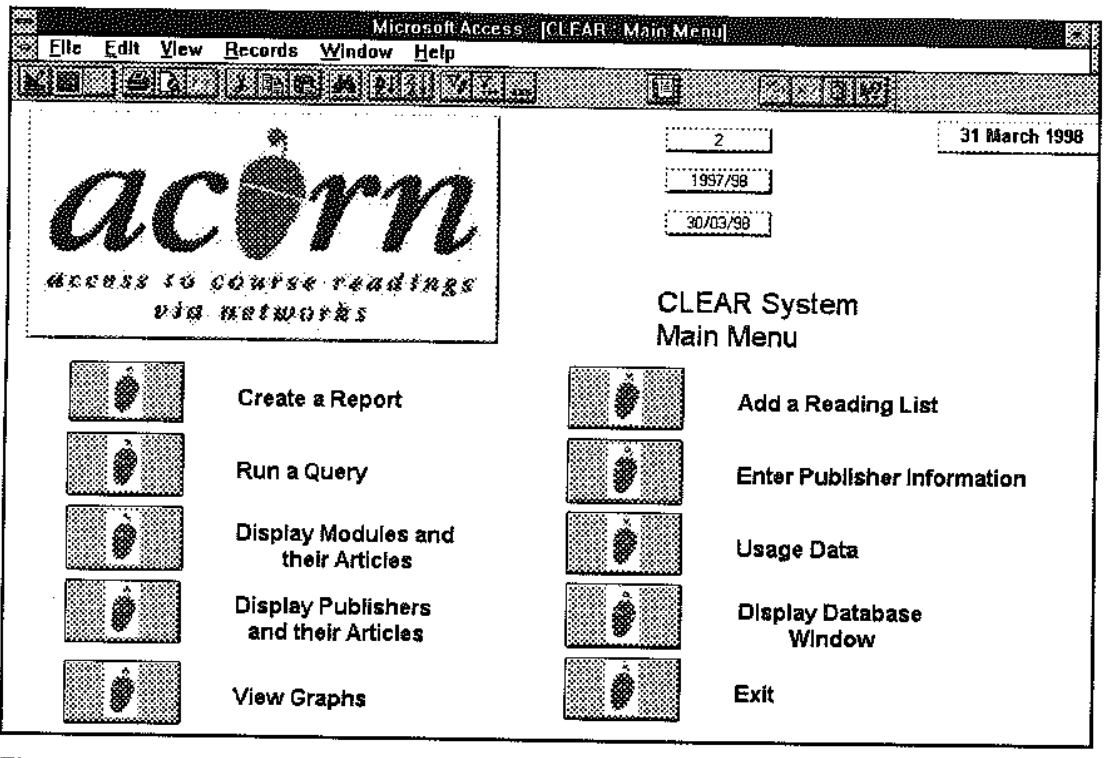

\section{CLEAR functionality}

Having spent eighteen months developing the database to meet the real needs of the project in copyright permissions seeking, CLEAR now offers a range of functions to facilitate every aspect of reading list data entry, permission seeking, and digitisation. The Main Menu offers links to the main functions of the database and is illustrated in Figure 3.

\section{Entering a Reading List}

Upon receiving a reading list from an academic, CLEAR allows the database operator to enter those details on the Add. The form firstly requests details relating to the reading list itself:

- Date Reading List was requested

- Date Reading List was received

- Module ID

- Module name

- Tutor name

- Department

- Academic session

- Starting semester

- Module Length

- No. of students 
- Start date

- Finish date

- Total no. of items on the list

- Total requested for ACORN

Pop-up menus are available for tutor name and department to save re-keying existing data. Default values have been set for the academic session, starting semester, module length, start and finish date fields as ACORN only dealt with one semester's readings at a time. Some data is requested purely for ACORN's project evaluation activities. This includes the date reading list was requested and received (to calculate average time taken to obtain a reading list), and the total number of items on the list, compared to the total requested for ACORN (to ascertain what proportion of reading lists constitutes high-demand journal articles). Other information, such as the number of students, is necessary for negotiating permissions and payment with publishers. Having entered the module reading list details, the articles attached to that reading list can be entered by means of the subform below. This form requests the standard bibliographic details of the articles. When a journal title is entered, CLEAR checks if that title already exists in its tables. If the journal is already on the database, the relevant PID and TID are added automatically and an AID is created by adding the unique record number to the TID. If the journal is new, a dialogue box requests whether the journal should be added. $A$ temporary AID is then created for replacement once the rights holder has been identified. At this point it will not be known whether the article is held in-house, or elsewhere (for example in ACORN's case, at Swets' backsets). By entering 'CHECK' in these fields, a report of the articles for location and backsets checking can

\section{Figure 4.}

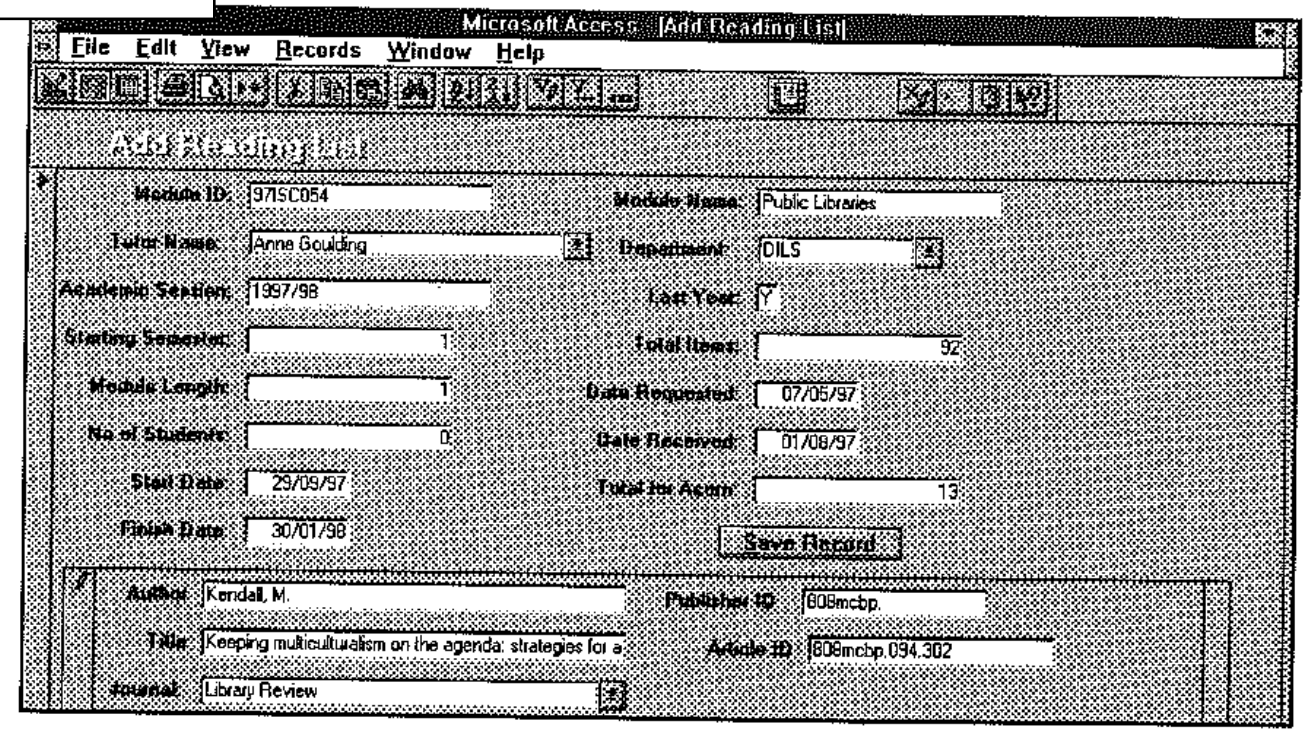

subsequently be generated.

\section{Locating Rights Holders}

Having entered the bibliographic details, it is necessary to locate the rights holders in the new journals.

The 'Create a

Report' option on the Main Menu provides a list of the most commonly used reports, one of which is the 'Journals without a publisher' report. Identifying rights holders is one of the most difficult elements of the copyright permission seeking process. It is 
particularly difficult to find a resource which provides all the information necessary to make a successful permission request, namely:

- Appropriate permissions contact name

- Contact's job title

- Publisher name

- Postal address

- Telephone number

- Fax number

- Email address

- Web address.

However, once identified, rights holder details are entered via the 'Enter Publisher Information' form, again accessible from the Main Menu. This form lists the journals for which there is currently no rights holder information. The database operator then creates a TID for the new journal from which the PID is extracted. The publisher information is then simply added to the fields on the form, and the 'Save Record' button used to write the information to the appropriate tables.

\section{Approaching Rights Holders}

The letter by which rights holders are approached for permission is integrated into CLEAR, as is the Agreement document and annex of articles for which permission is being sought. Batches of permissions letters and agreements can easily be printed off the database, along with mailing labels. When letters have been sent, a 'query', or programme, is run to update CLEAR with the request dates. This ensures that the same request is not sent twice.

\section{Negotiating with Rights Holders}

Most libraries are familiar with claiming orders from suppliers, and electronic copyright permissions are no exception. In fact, because electronic copyright permission requests are fairly new phenomena, many rights holders have no licensing policy, and can take a long time to respond. In order to 'chase' publishers, CLEAR automatically generates 'Rights Holders to Chase' reports which appear when the database is opened. The system selects only rights holders for which no progress information has been added in the last two weeks, and the reports are divided into British and Overseas rights holders because of potential differences in

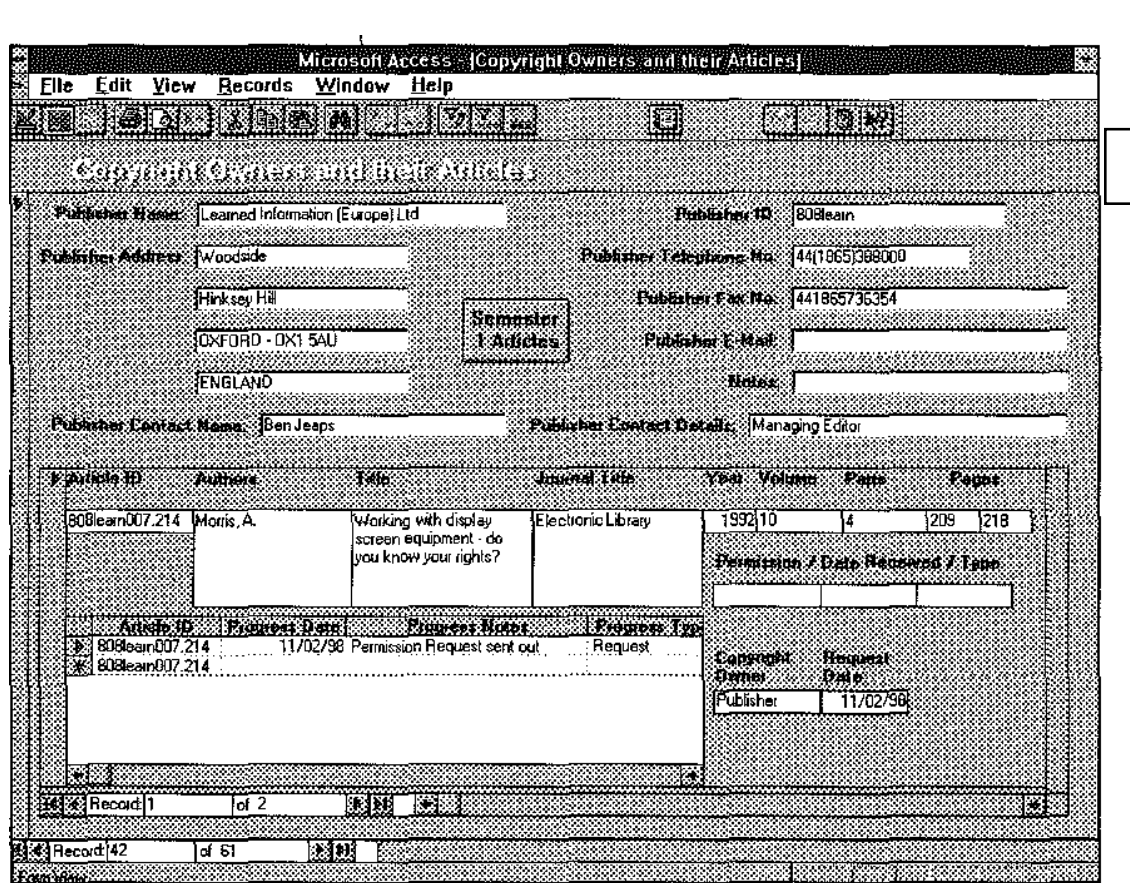
approach. While chasing rights holders, the database operator

Figure 5. he copyrngm Owners and their Articles' form which lists all articles requested by rights holder (Figure 5).

The rights holder's contact information is 
visible at the top of the form, and in the sub-form beneath the articles relating to those rights holders are listed. In addition to listing the articles, the number of students on the module for which that article has been requested is given to assist in negotiating any fees or conditions. When progress has been made with a rights holder it is entered in the progress date, notes, and type fields. The progress type field allows the database operator to designate whether the progress was a 'chase' on our behalf or a 'response' from the rights holder. When a decision has been taken by the rights holder, 'received' or 'denied' is entered into the permission field, and when the Agreement has actually been signed, the date is entered into the permission date field. ACORN's experience has shown that the average number of chases per article is almost six, with $77 \%$ of rights holders requiring chasing. If there are any special conditions to the agreement, these can be entered into the free-text notes field. Payment details are entered into the permission type field. The permissible values are 'Free', 'Licence', or 'Royalty'. To CLEAR, a licence is a one-off payment which will be written to the licence table, and a royalty is a usage-based formula for writing to the royalty table. Appropriate fees are then calculated and forwarded to the rights holder.

\section{Liaising with academics}

As the permissions process is a lengthy and unpredictable one, there is often the need to liaise with academics regarding progress- particularly refusals. For this purpose CLEAR has a 'Modules and their Articles' form which displays the permissions progress for each articles on a particular reading list. This form can easily be opened when a phone call is received from an academic. Similar information is in report form for sending progress reports to academics throughout the permission-seeking process.

\section{Ordering the copy}

Once the Permission field has been updated to 'Received' status, the article details are written to a 'New Permissions Received' report. This report indicates whether the articles are available in-house or whether, in ACORN's case, they were available at Swets Backsets. ACORN discovered that high demand in-house journals were often in too poor a condition to scan, so some articles were instead ordered from the British Library via Inter-Library Loan (ILL). Having printed out the New Permissions report, a query is then run to update CLEAR to the effect that those permissions have begun the digitisation process. An ILL order report prints out new ILL requests, and CLEAR is updated in the same way, to indicate which articles are on order at the British Library. When ILLs are received they are receipted onto the system via another form, and sent with the 'New Permissions Received' report to the digitisation service. Swets \& Zeitlinger, B.V. undertook ACORN's digitisation at their Microspore in Holland. Electronic copies are receipted on CLEAR, and made available via Loughborough University's TalisWeb OPAC, and a Web Pages route. A 'dummy' demonstration of the ACORN Service is accessible via the ACORN Web Site. (acorn.lboro.ac.uk/ demo/demo.htm)

\section{Usage information}

One of the benefits to rights holders of participating with ACORN was the detailed usage statistics we were able to provide back to them. The ACORN Service itself logged the following usage data:

- Article ID

- Username (giving department and year of user)

- Access point (location of PC) 
- Access route (OPAC or Web pages)

- Activity (view only, view and print, or print only)

- Number of pages printed, if any

- Date and time session opened

- Date and time session closed

This enabled us to provide usage statistics of individual articles, as well as a general

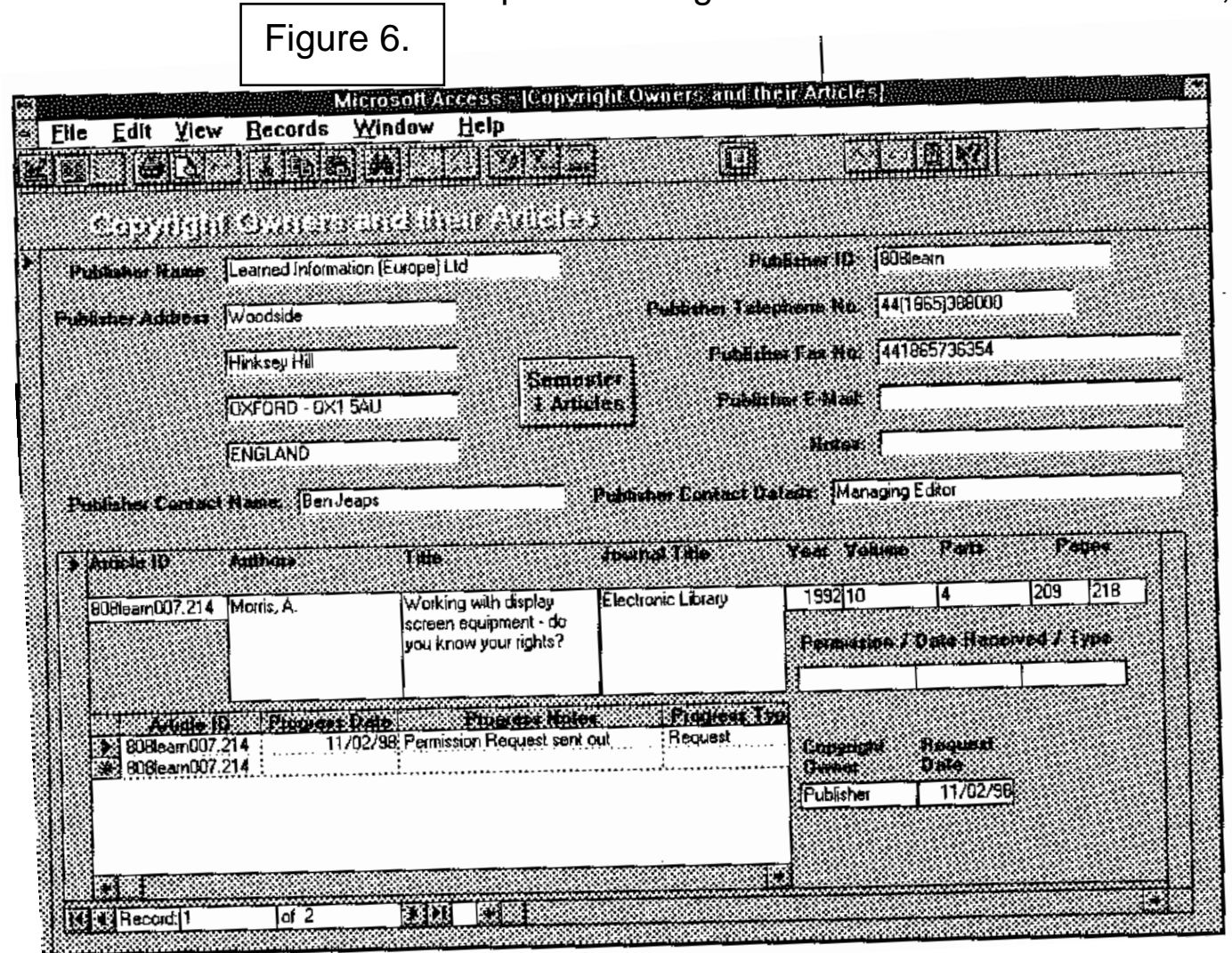

usage

overview

report back to

the rights

holder.

Weekly usage

data was

uploaded from

the ACORN

delivery

mechanism

onto CLEAR

and a variety

of usage

reports and

graphs were

available via

the 'Usage

data' option on

the Main

Menu (Figure

6).

\section{Management information}

In addition to enabling Project ACORN to competently manage the permissions process, the other great benefit of CLEAR was its reporting functionality. There are just under 100 reports available via the Reports Table which analyse the rights management data in a multitude of ways. Examples of the types of reports available are given below:

\section{1. Project information}

In order to analyse and cost the permissions process, reports were designed that gave the project detailed chasing and usage statistics. Examples of such reports include: the average number of chases per article per semester; the average number of pages of an article by department; the average time taken to gain permission; and the proportion of registered students using ACORN.

\subsection{Reports for academics}

To keep academics up to date with permissions progress, academic staff update reports were designed. These list the articles by module and give the permission status (that is received, denied or pending) and publisher. The greatest value of the academic update reports to ACORN was that where an academic had a good relationship with a publisher that had refused permission, they were sometimes able to lobby the publisher on ACORN's behalf. Usage reports by module were also 
available. These allowed academics to see exactly how many uses of their readings had been made, and whether these were viewing or printing activities.

\subsection{Reports for publishers}

Publishers were provided with a full permissions survey, in addition to the general usage reports and individual article usage reports as one of the benefits of participating with the project. The reports that contributed to the permission survey included an article provider report (that is what proportion of the ACORN articles were available from stock a Loughborough, provided by the publisher, and soon); copyright ownership report (that is what proportion of the copyright in the articles was owned by publishers, editors, authors and so on); module permissions (that is how permissions and refusals affected individual module coverage); response rates by publisher type, and many more.

As CLEAR gave ACORN access to a great deal of information, much of it personal data relating to usage and commercially sensitive data relating to rights holders, the decision was taken to write an Information Policy.

(acorn.Iboro.ac.uk/reports/infopo.htm) This stated what information we would and would not provide to particular stakeholder groups and to what timescales.

Fortunately ACORN had no need to cite the Policy at anyone, but it acted as a safeguard against any request from, say, an academic who wanted to know whether student $X$ had actually read the article s/he cited in their dissertation.

\section{Conclusion}

More and more Hells are looking to the electronic provision of high demand materials for their students, and will, for the time being, be faced with the need to approach rights holders individually for perm mission to do so. Due to the complexity of the copyright, liaison and digitisation processes, such HEis will need an effective means of managing their permission seeking operations. Although there are a number of commercially available ECMSs, their cost is not geared for the HE sector. In time, it may be that Library Management System suppliers incorporate permissions tracking functionality into their systems, indeed many of the permission seeking processes closely map existing library ordering, claiming and reporting functions. However, until then, it is hoped that Project ACORN's CLEAR ECMS can act as a template for libraries in the design of ECMSs for their own permission seeking activities.

(C) Elizabeth Gadd, Richard Goodman, and Adrienne

Muir, 1998.

\section{References}

Copyright Licensing Agency, Higher Education Licence

URL: http://www.cla.co/www/sectors.htm\#HE

Copyright, Designs and Patents Act 1988: Elizabeth II:

Chapter 48, Section 17 London: HMSO, 1993.

Digital Libraries Initiative URL:

http://www.cise.nsf.gov/iis/dli home.html

The Digital Object Identifier System URL: http://www.doi.org/index.html

EARL: Electronic Access to Resources in Libraries

URL: http://www.earl.org.uklinformation/about.html

Elib Electronic Libraries Programme URL: http://ukoln.bath.ac.uklservices/elib/

ERCOMS Market survey of existing electronic copyright management systems

(ECMS) and projects URL:

http://www.iielr.dmu.ac.uk/Projects/ERCOMS/ercomsm.html 
Intellectual Multimedia Property Rights Model and Terms of Universal Reference URL: http://www.imprimatur.alcs.co.uk/

Project ACORN Information Policy, URL:

http://acorn.lboro.ac.uk/reports/infopo.htm

Project ACORN Service Demonstration, URL:

http://acorn.lboro.ac.uk/demo/demo.htm

Project ACORN URL: http://acorn.Iboro.ac.uk

Swets \& Zeitlinger, B.V. URL: http://www.swets.nl/

The UK Office for Library and Information Networking

URL: http://ukoln.bath.ac.uk/ 